\title{
Leopoldo Alas y su actitud ante la lengua
}

\author{
JOSÉ M. NAVARRO ADRIAENSENS
}

Universidad de Bremen

Nuestros escritores del XIX - la mayoría de los cuales sobrevive trabajando para la prensa - tienen una actitud crítica ante el estilo y gramática de sus contemporáneos, de la que apenas queda huella hoy. Y no, precisamente, porque haya mejorado el conocimiento de la lengua en los periodistas actuales, ni mucho menos. Esa actitud, que a lo largo de la generación llamada del 98 se va a acentuar, refleja en gran medida posturas preceptivas. La Real Academia hace sentir su peso como autoridad reglamentadora y parece como si no se hubiera dado cuenta de un hecho tan natural y visible como el cambio lingüístico. Naturalmente, los criterios de buen decir y de la construcción correcta vienen acompañados $-\mathrm{y}$, tácitamente, marcados- por el decir de la gente culta. Y todavía hoy, cuando ya nadie hace caso de actitudes preceptivas en materia de lengua, sigue prevaleciendo el criterio de la regla y la corrección, a veces incluso a espaldas de la norma lingüística, muchas veces dinamizada por construcciones y giros que más proceden de la ignorancia que de la necesidad innovadora, pero inexorable en cuan- 
to a su establecimiento de nuevos criterios de aceptabilidad y, por tanto, de una nueva norma.

En este sentido nos sorprende la actitud de Leopoldo Alas, «Clarín», ante la lengua. Pocos escritores del XIX adoptan una postura teórica ante el proceso cambiante del lenguaje y la fuerza motriz del cambio, en ocasiones indiferente a los principios preceptivos. Estableciendo una irónica comparación con la política, escribe "Clarín»: «Además, las palabras no se votan como una ley cualquiera; la soberanía nacional, que en su materia legislativa es un puro tropo, en que se toma al Gobierno por el pueblo, es una verdad, una realidad, en materia de lenguaje» ${ }^{1}$.

Creación y cambio lingüístico son ya para «Clarín» -anticipándose a criterios vigentes —realización y creación inmediata de los hablantes: «Se habla como se puede; se crea el lenguaje naturalmente; sale de las entrañas del pueblo, como del derecho decía Savigny, y no hay que darle vueltas ${ }^{2}$. Del mismo modo queda perfectamente claro para él que el criterio de aceptabilidad establecido por la norma de la comunidad hablante, mantiene la vigencia del término acuñado o la contrucción admitida, hasta que se imponga un nuevo cambio:

Pero una vez nacida la palabra, ya no se la puede profanar ni falsificar impunemente: su valor expresivo es un símbolo del espíritu nacional, y no es cuestión bizantina o constantinopolitana la de ver cómo se debe hablar para hablar como se debe ${ }^{3}$.

Con todo, «Clarín» establece con toda precisión la diferencia entre «el empleo corriente y utilitario del idioma» y «el lenguaje como instrumento artístico».

Estos comentarios de Leopoldo Alas sobre la norma lingüística ván incluidos a propósito de una discusión de doña Emilia Pardo Bazán con algunas personalidades sobre la forma adecuada del presente de indicativo del verbo abolir: abolo, abuelo o abulo. «Clarín» esgrime su vena sarcástica más acerada, para ridiculizar tal documento de incompetencia gramatical ${ }^{4}$.

El propio Leopoldo Alas ha dado pruebas en su producción literaria de su valoración de giros y expresiones regionales. Se podría objetar

1 «Clarín»: Paliques (Segunda Sección: Satura. Bizantinismo), Madrid, Librería de Victoriano Suárez, 1983, p. 140.

2 Ibid., p. 140.

3 Ibid., p. 141.

4 Ibid., p. 141. 
que, dado el impulso que el Naturalismo literario había dado a giros y expresiones locales y teniendo en cuenta la admiración de Alas por Zola, se trataba de un rasgo que traía consigo la época.

En primer lugar, el estudioso que haya seguido con detenimiento la obra, diversa y a veces contradictoria, de «Clarín» sabe que nada queda más lejos de su actitud que el apresuramiento a abrazarse a una nueva corriente literaria, política o filosófica, sin una detenida reflexión. Tal vez sea esto lo que más le aproxime a nuestros escritores del 98: su constante llamada a la reflexión y al estudio, su «alergia» a las corrientes nuevas por el mero hecho de su novedad. No es necesario ni oportuno insistir aquí en este aspecto, que se sale de nuestro tema, pero recordemos su sólido conocimiento de Zola y su admiración por él y, al mismo tiempo, su crítica de las desviaciones naturalistas; su admiración por Baudelaire, su detenido estudio de la Filosofía y la Literatura europea, lo convierten en uno de los críticos más violentos de la ñoñez y de la superficialidad de eruditos a la violeta, como él mismo dice, remedando a Cadalso.

Detengámonos en algunas observaciones sobre el lenguaje asturiano rural, presente en su obra. En el cuento ;Adiós, Cordera! ${ }^{5}$, aparecen con frecuencia términos y expresiones locales: los niños, Rosa y Pinín, se encargan de llindar, es decir, de cuidar de la Cordera, la vaca de los campesinos; ellos consiguen y cambian el «narvaso para estrar el lecho caliente de la vaca», es decir, la caña del maíz para preparar la «cama» de la Cordera; el padre de Rosa y Pinín es casero, que significa, a diferencia de su parónimo castellano, arrendatario de una casería o finca de labranza, cuyo propietario es el amo; la organización administrativa se regula por medio de las parroquias que, igual que en Galicia, corresponden a pequeñas entidades comunales, a veces mínimas, que constituyen divisiones administrativas dentro del municipio. Rosa y Pinín están sentados sobre un montón de cucho, es decir, de estiércol. En algunas expresiones conversacionales o familiares que aparecen en el mismo cuento, "Clarín» refleja con toda inmediatez el ambiente campesino asturiano: mío pa (mi padre), ineños, acá vos digo; basta de pamemes! (¡niños, venid aquí, basta de pamemas!). En todo caso, las expresiones y términos quedan incluidos en el texto correspondiente de tal manera que su contexto inmediato ayuda a comprenderlos. Los términos agrícolas y administrativos ejercen una función no sólo ambiental, ya que su versión castellana habría requerido en la mayoría de los

5 ¡Adiós, «Cordera»!, Madrid, Ed. Espasa-Calpe, S. A., pp. 14, 15 et pássim. 
casos la correspondiente explicación. Baste este pequeño ejemplo de uno de los cuentos más conocidos de Alas.

También en el uso de este rasgo naturalista «Clarín» hará presidir su sentido de la ponderación y el equilibrio, lejos siempre de corrientes y modalidades que no estén en armonía con criterios artísticos o de buen gusto. Prueba de ello es su crítica de algunas expresiones locales aparecidas en $E l$ sabor de la tierruca de Pereda. En su reseña de esta obra, escribe «Clarín»: «Las calabazas que da (Nisco) a Catalina son soberbias, y vale más todavía el cortísimo diálogo de los dos amantes en la calleja. "Hispete puro, que mañana te pelan", dice Catalina, y contesta Nisco: “'Taday, pobreza!’. Magnífico, señor Pereda; magnífico» ${ }^{6}$.

Mayor interés tienen las observaciones de «Clarín» sobre corrección léxica y gramatical. La mayoría de sus críticas sigue conservando su vigencia, lo que no significa, ni mucho menos, que haya mejorado el uso ni en el campo literario ni mucho menos en el estilo periodístico $u$ oratorio.

Entre los ejemplos seleccionados de observaciones críticas sobre el léxico de sus contemporáneos, mencionemos una ligera objeción - sin la virulencia tan frecuente en "Clarín»- al uso del término azararse en lugar de azorarse. Refiriéndose a la novela de Emilia Pardo Bazán La prueba, escribe «Clarín»: «En la página 15 leo: "La veo que saluda a un señor... y al saludarlo se azara bastante." Ese azara ¿es de doña Emilia o del cajista? Los jugadores de billar, que además no saben gramática, suelen decir azararse no sólo cuando se trata de azares, sino de turbaciones, v. g.: "Se azara si pierde." Pero yo no creo que doña Emilia opine que el verbo azararse puede ser usado en vez de azorarse» ${ }^{7}$. La observación de "Clarín», casi en la encrucijada de dos siglos, es muy comedida e incluso aduce el testimonio de un uso popular que acabará generalizándose. En efecto: el originario azorarse, derivado del sobresalto que el azor produce en las aves que persigue, se convirtió en azararse en nuestro siglo, influido posiblemente por azar o bien, según opina Corominas, por influjo del gitanismo acharar ( = avergonzar). Se trata de un modelo de cambio lingüístico, caracterizado por la sucesiva pérdida de la conciencia semántica del término primitivo - azor >azorarse-, y la atracción analógica de un término próximo, que decide su aceptación generalizada.

6 «El sabor de la tierruca», de Pereda, en «Clarín», Obra Olvidada, Ediciones Júcar, Madrid, 1973, p. 43.

7 Palique (Madrid Cómico, 25-10-1890), en «Clarín», Obra Olvidada, cit., p. 95. 
Consecuente con el criterio de la norma, mantenido por «Clarín», es su actitud ante los galicismos y tecnicismos. En este sentido, se mantiene abierto ante el uso del neologismo realmente aceptado, es decir, ante el término que desempeña una función admitida por la colectividad hablante. El mismo hará uso de galicismos, aunque observamos un reparo latente en su empleo - lo mismo que cuando se trata de términos aún no incorporados al diccionario-, como refleja el hecho de presentarlos casi siempre entrecomillados. Donde se evidencia su crítica es en aquellos casos en que el «usuario» del término ni siquiera domina su verdadero significado. Un ejemplo evidente lo ofrece en su reseña de La prueba, de la Pardo Bazán: «Lo peor de aquí es el tecnicismo, que aunque no abunda, daña, por venir en pésimas ocasiones. A veces, donde debía haber frases de pasión, de naturalidad, sinceridad y fuerza plástica... nos encontramos con palabrotas de botica. Doña Emilia le atribuye a la palabra álcali una virtud plasmante que no tiene. En cierta página hay una equimosis digna de don Hermógenes; valga la verdad, doña Emilia debiera comprender que ese tecnicismo de primer año de medicina es el mismo con que se dan tono los malos revisteros de tauromaquia, que describen las heridas de los diestros y de los caballos con el estilo de los médicos y hasta de los veterinarios ${ }^{8}$.

«Clarín» llega a crear un término para describir esta nueva ola del lenguaje técnico: gongorismo politécnico.

En cuanto a los galicismos o, mejor dicho, las interferencias léxicas interlinguales, baste recordar su referencia a la traducción del francés de un periodista «que acaba de descubrir una vajilla de Napoleón compuesta, dice, de "platos, asientos, vasos, etc.". ¿Una vajilla con asientos? ¿Si será que el traductor de la noticia tomó por asientos los platos y por platos las fuentes? Así se escribe la historia... de Napoleón's ${ }^{9}$.

Con mayor rigor crítico sale «Clarín» al paso de las infracciones gramaticales. En muchas ocasiones, al reseñar obras de poetas noveles, hace hincapié tanto en las inadecuadas construcciones como en evidentes errores gramaticales. Tampoco salió bien parada de sus críticas

8 Ibid., p. 93.

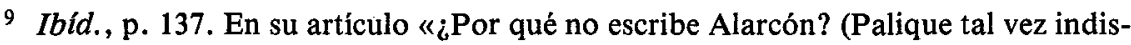
creto)» (Madrid Cómico, 4-1-1885), ibíd., p. 57, "Clarín» había comentado irónicamente que la Academia censura en su Gramática el uso de galicismos: «En esto la Academia en masa peca contra sus propias órdenes. ¿No dice que se prohibe el galicismo? Pues qué mayor galicismo que ella, que está tomada de una institución francesa por un rey que nos vino de Francia?» 
Emilia Pardo Bazán. En su reseña de Morriña escribe Alas: «¿Se puede usar el gerundio como lo usa ella muchas veces en este libro? ¿Se puede decir desandó por desanduvo, como dice doña Emilia dos veces en su colección La dama joven, y otra no recuerdo dónde?» ${ }^{10}$

Más violenta es su crítica de un error gramatical del P. Blanco García en La Literatura Española en el siglo XIX. «Clarín» escribe: «Figurémonos que un historiador de La Literatura Española en el siglo $X I X$ escribe desdirían. ¿Qué le llamarían los Zoilos más severos? Pues erudito a la violeta: porque se mete en historias literarias sin saber conjugar verbos irregulares...», «... el historiador que dice desdirian en vez de desdecirían no es un erudito a la violeta, ni cosa alguna que huela bien; será un erudito al ajo del arriero ". ${ }^{11}$ Alas incluye, como en muchas otras ocasiones, cierta malicia que trasluce su conocido anticlericalismo: «Tal vez entre las licencias necesarias con que el $P$. Blanco se ha hecho fuerte, está la licencia necesaria para conjugar mal.» En su artículo «La muiñeira» ${ }^{12}$ - juego de palabras con el que alude al P. Muiños, agustino como el P. Blanco García-y, posteriormente, en «Entre faldas ${ }^{13}$, en el que insiste en su acerada crítica contra este último, vuelve a insistir en errores léxicos y gramaticales de ambos, dejando entrever además cierta actitud de polémica personal. En el segundo de los artículos vuelve a subrayar el error gramatical del P. Blanco anteriormente mencionado. Curiosamente, la observación gramatical de «Clarín» dio lugar a un conato de polémica que cortó de modo tajante su autoridad en materia de gramática.

En ocasiones sorprende el tono acre y el ataque personal, duramente polémico, en un hombre como «Clarín», que por su autoridad en cuestiones de la lengua, no tiene necesidad de ello para dejar en rídiculo a sus criticados. Y sorprende sobre todo porque la actitud de Alas es predominantemente ponderada. Esa actitud de equilibrio caracteriza precisamente toda su concepción del uso de la lengua. El artículo «Entre faldas» refleja muy bien la amargura de "Clarín» ante los ataques, unas veces abiertos, otras, mediante tercerías, de Muiños y Blanco contra él.

Citemos, por último, un pasaje muy representativo de la crítica de «Clarín» contra impropiedades gramaticales y estilísticas, unida a un

\footnotetext{
10 Ibid., p. 74.

11 Paliques, p. 148.

12 Ibid. (Tercera Sección: Palique. Muiñeira), pp. 249-262.

13 Ibid., pp. 263-275.
} 
aniquilador ataque personal; en su «Palique» publicado como carta abierta a don Silverio de la Torre, propietario de la Revista Moderna, nuestro autor inserta una serie de errores léxicos, ortográficos y gramaticales de Navarro Ledesma, que firmaba con el seudónimo «Calínez», y concluye:

Y no hay para qué detenerse a considerar las apretadas macollas del trigo, ni la hosca funebridad del invierno. Tú sí que eres fúnebre, Calínez; un payaso fúnebre, macabro, como diría quien yo me sé. No hay para qué seguir. citando dislates. Lo peor es la pedantería sosa, la funebridad hosca de ese melocotón invernizo, que usted, señor La Torre, tiene encargado de la crónica semanal.

Prescinda usted de sus flacos servicios, y déjelo; como le irán dejando en todas partes, hasta que tenga que refugiarse en Deusto o en Loyola, en calidad de hermano cocinero o encargado de planchado de albas y roquetes ${ }^{14}$.

La actitud crítica de «Clarín» respecto a la Real Academia de la Lengua ha de analizarse separando la institución, vista en el contexto político del momento, de sus tareas.

Alas ejerce una violenta crítica contra aquellos personajes admitidos como miembros de la Academia sin los méritos suficientes:

La Academia ya no sirve ni para hacernos reír.

$\mathrm{Su}$ descrédito es tal, que ya no escandalizan a nadie las escandalosas elecciones que estamos viendo cada vez que se muere un inmortal. Las injusticias académicas son ya a los fueros del buen gusto y de la literatura nacional, lo que es a la honestidad la última cópula de la scortum callejera. ¿Qué importa una liviandad más después de tantas liviandades? ${ }^{15}$.

Este violento ataque se produce con ocasión del ingreso en la Academia de Antonio María Fabié.

«Clarín», refiriéndose a la «traducción de la traducción de Vera de la Lógica de Hegel», escribe: «Fabié, que no sabe alemán, tampoco sabe español; de modo que es un apóstol del hegelianismo que está muy lejos de tener el don de lenguas» ${ }^{16}$. Tras pasar revista a algunas formulaciones disparatadas de Fabié - «la existencia es el vestigio de la actividad», «el pensamiento unilateral», «la India es el momento inmediato del espíritu; Grecia es la reflexión externa»-, concluye: «Lo que hay es que Fabié no sabe expresar en español lo que no ha entendido en francés o en italiano y fue pensado en alemán.» Su crítica de este académico queda resumida así: «En fin, no hay cosa más ridícula en el mundo que

14 Obra Olvidada, p. 260.

15 Paliques, pp.. 329-330.

16 Ibíd., p. 332. 
el hegelianismo de Fabié, sobre todo desde el punto de vista de la gramática castellana». ${ }^{17}$

Precisamente esta crítica de «Clarín» es una prueba de su alta consideración de la Academia y un toque de alerta ante el proceso de politización, con la consiguiente pérdida de nivel «académico» que se está produciendo. Así es como debe interpretarse, en mi opinión, el amargo subrayado irónico de «Clarín»: «No cometeré, pues, la injusticia de decir que Fabié no es digno de entrar en la compañía de solecismos mutuos de la calle de Valverde. Lo es. No será el último, ni el peor.» ${ }^{18}$.

Frente a estos ataques contra la degeneración institucional a través de la incapacidad de algunos miembros elegidos, «Clarín» mantendrá, en general, el criterio de la Academia en materia de lengua y léxico, como referencia y autoridad, en sus observaciones sobre la lengua.

Así pues, en su actitud ante la lengua y su uso, Alas utilizará con valor de autoridad referencial el criterio de la Academia, aunque no en virtud de su función preceptiva, sino orientadora. Al mismo tiempo señalará, como tantos otros críticos contemporáneos y posteriores, la tendencia a anquilosarse, mecida en los laureles de una autoridad preceptiva, que no convive con suficiente agilidad el fenómeno del cambio lingüístico y su conformación de la norma. «Clarín» es totalmente consciente de esta movilidad y del enorme impacto de los nuevos tiempos en el uso de la lengua, pero también es un cuidadoso vigilante y ágil crítico de las alteraciones de la norma, no motivadas por necesidades expresivas sino por ignorancia. Sin perjuicio de que, en muchas ocasiones, la anomalía pueda dar lugar a un patrón generalizado y, finalmente, aceptado.

La preocupación ante una posible pérdida de la orientación en el

17 Ibid., p. 333.

18 Ibíd., p. 330. Martínez Cachero, en la nota 42 de su edición de Palique (Barcelona, Ed. Labor, S. A., 1973), insiste, como otros estudiosos de «Clarín», en la actitud de éste en contra de la Real Academia Española de la Lengua: «Clarín militó siempre contra la Real Academia Española de la Lengua y dijo mal de algunos académicos contemporáneos suyos. Entendía que ni en el aspecto lingüístico - con la Gramática y el Diccionario- ni en el literario - con los certámenes que convocaba - cumplía adecuadamente la Academia sus específicas misiones; le irritaba, además, la politización creciente de la docta corporación.» En mi opinión, Martínez Cachero ha sabido ver los dos aspectos de su crítica, pero creo que puede mantenerse una clara diferencia de actitud en «Clarín» respecto a las dos vertientes de la institución. La misma frase de "Clarín», que da lugar a la nota anterior es una prueba más de esto: «No se debe hacer sistemáticamente la oposición a nada, y menos a la Academia, con quien se puede ser muy justo sin ser ministerial casi nunca» (ibid., p. 140). 
campo de la estética es una de las constantes de «Clarín». De este pensamiento deja clara constancia en el prólogo a sus «Paliques»:

Decir que ya no hay reglas y sostener que todavía hay arte es un contrasentido. Se confunde por muchos la necesidad general de la regla con las malas reglas históricas, o con las que fueron buenas para tales circunstancias y ya no lo son para otras ${ }^{19}$.

${ }^{19}$ Op. cit., p. XIV. 